\title{
A virada para o século XXI e os desdobramentos das concepções pós-modernas nas políticas de gestão escolar
}

\author{
Isaura Monica Souza Zanardini*
}

Maria Elizabete Sampaio Prado Xavier**

\section{Resumo}

Este artigo apresenta reflexóes a respeito da reforma da gestão escolar a partir da década de 1990. Esta reforma é implantada sob o argumento de que é necessario modernizar a perspectiva de gestão da escola para torná-la eficiente. Para desenvolver a análise, realizada a partir de pesquisa bibliográfica, o artigo revisita a substituição do taylorismo/fordismo pelo paradigma da acumulaçáo flexível, que apresenta um "novo" modelo de gestáo e de controle. Este modelo estaria pautado na ideologia da pós-modernidade. Para evidenciar esta conclusão, discute-se a lógica de gestão/ controle do trabalho pautada na racionalidade pós-moderna que acompanha a recuperação dos ideais do liberalismo, procurando apresentar as implicaçóes que essa lógica produz no âmbito da gestão escolar. Observa-se que a organização escolar incorpora este movimento por meio da difusáo de hábitos e atitudes e também a partir da adoçáo dos elementos empregados pela administraçáo que se desenvolve em um conjunto de organizaçóes sociais. Nesse sentido, é tratada a valorização do elemento humano, da implantação de mecanismos de avaliação, da descentralização e autonomia que constituem-se como categorias fundamentais para a reforma da gestão em análise. Como um dos resultados evidenciados, destaca-se que a tensão entre as "racionalidades" discutida pela pós-modernidade é de base ideológica e tem em vista a responsabilização dos sujeitos pelos resultados alcançados.

Palavras-chave: Gestão escolar. Racionalidade. Pós-modernidade.

\footnotetext{
* Doutora em Educação pela Universidade Estadual de Campinas (UNICAMP). Professora do Curso de Pedagogia e da Pós-Graduaçáo em Educação da Universidade Estadual do Oeste do Paraná (UNIOESTE).

** Doutora em Educação pela Pontifícia Universidade Católica de São Paulo (PUC/SP). Professora do Programa de Pós-Graduação em Educação da Faculdade de Educação da Universidade Estadual de Campinas (UNICAMP).
} 


\section{Introdução}

Assim como a educação tem sido historicamente chamada a resolver problemas culturais, sociais e econômicos que se colocam no contexto de afirmação de determinadas relações sociais, a gestão escolar tem ocupado papel de destaque nos embates educacionais, sendo mesmo apontada como responsável pela falta de sucesso de tais políticas, e, em consequência, pelo atraso educacional no país.

Essa perpectiva centrada na preocupação com a qualidade e adequação da gestão escolar pode ser encontrada, por exemplo, no contexto da década de 1980 quando, em meio ao processo de "redemocratizaçáo" da sociedade brasileira, afirmava-se a necessidade de constituir uma gestão mais democrática e participativa e, desse modo, atender ao movimento de expansáo da escola pública.

A necessidade de promover a "modernização" da gestão escolar alardeada particularmente a partir da década de 1990, tendo em vista a implementação de uma gestáo eficiente e "democrática", orientada pelo controle dos resultados e náo dos processos e pela valorizaçáo do elmento humano e por um determinado envolvimento da comunidade nos resultados alcançados pela escola, sustentavase no argumento da racionalização do trabalho pedagógico e da gestáo escolar, na discussão a respeito da substituição do taylorismo-fordismo, e da forma de gestão que acompanhou esse modelo de produção, pelo novo paradigma da acumulaçáo flexível. No contexto do neoliberalismo e da pós-modernidade, tomada aqui como uma expressão ideológica do padrão atual de acumulação do capital, difundiu-se rapidamente a noção do esgotamento dos velhos modelos, apresentando-se um "novo" modelo de gestão e/ou controle sobre o trabalho e sobre os homens.

Destacamos esse fato para chamar a atenção para os condicionantes da divisão do trabalho que se estabelece na escola ao sofrer as determinações do modo de produçấo capitalista, reproduzindo em grande medida a sua lógica e cumprindo tarefas específicas. Como afirma Tragtenberg (2002, p. 13), “[...] não há dúvida de que a escola, em qualquer sociedade, tende a renovar-se e ampliar seu âmbito de ação, para reproduzir as condições de existência social, através da formação de pessoas aptas a ocupar os lugares que a estrutura social oferece".

Nessa direção, para reproduzir a lógica do capital, é preciso que a escola, assim como outras organizaçóes sociais, ocupe-se daquilo que chamamos de 
controle ideológico do trabalho. Essa tarefa é desempenhada não apenas através da difusão/socialização de hábitos e atitudes, mas a partir da adoção dos mecanismos/estratégias pela administração/gestão que se desenvolve no conjunto das organizaçóes/instituiçóes sociais. Assim, a escola reproduz a lógica do capital no espaço da difusão do conhecimento, e também no espaço da organização do trabalho que é por ela realizado.

Partimos do pressuposto de que a defesa da concepção capitalista de administração na gestão dos sistemas e unidades escolares é feita sob o pretexto de que, embora as organizações tenham objetivos diferentes, elas são semelhantes e, para que sejam eficientes, é preciso que sejam geridas, administradas e organizadas a partir de pressupostos que já se mostraram eficientes em outras organizaçóes. Nessa mesma direção, de acordo com Félix (1986), o objetivo da administração escolar seria equiparar o sistema escolar às organizaçóes que alcançam altos índices de racionalidade, eficiência e produtividade, na busca de uma cientificidade mercadológica para a organização dos sistemas e unidades educacionais.

É preciso considerar que o movimento de adequação da gestão das empresas e do controle sobre o trabalho na organização dos sistemas e unidades educacionais aos princípios de eficiência e racionalidade capitalista não ocorre de uma forma linear e imediata, até mesmo porque, embora com muitas semelhanças, escola e empresa capitalista são marcadas por particularidades e especificidades, bem como somam-se a outras instituiçôes/organizações sociais, na medida em que produzem/reproduzem um determinado padrão de comportamento social.

Isso significa que não há uma mera reprodução da administração empresarial na administraçáo escolar ou uma transposiçáo da perspectiva de gestáo/controle do trabalho implantada na empresa capitalista para a escola, mas que se estabelece entre elas uma estreita ligação mediada pelas modificaçôes que ocorrem no âmbito do padrão capitalista de produção e acumulação. Nessa lógica, as diferentes organizaçóes sociais reproduzem a mesma perspectiva de gestáo e de controle do trabalho, porque são produzidas em um mesmo contexto político, econômico e social, o qual exige a reproduçáo de uma dada racionalidade.

A fim de explicitar esse movimento, tratamos nesta reflexão da lógica de gestão/controle do trabalho pautada na racionalidade pós-moderna que 
acompanha a recuperação dos ideais do liberalismo, procurando apresentar as implicações que essa lógica produz no âmbito da gestão escolar. Como subsídio para a análise, apresentamos, em linhas gerais, algumas consideraçôes de Max Weber (1991) sobre a racionalidade do capitalismo moderno, que se expressa nas diversas instituições sociais modernas e pós-modernas, garantindo a acumulação capitalista e a reprodução desse modo de produção.

\section{Os desdobramentos das concepções pós-modernas: considerações sobre a racionalidade}

Para compreender a relação da ideologia da pós-modernidade com as transformaçóes que, nesse contexto, são requeridas para a racionalidade, a gestão e o controle do trabalho, particularmente nas instituiçóes sociais, recuperamos uma Conferência proferida por Michel Maffesoli (1994) no VI Colóquio PanAmericano de Investigação em Enfermagem, realizado em Ribeirão Preto, intitulada "Estudo Crítico das Ciências, da Formação e das Condições do Conhecimento Científico", que realizou a defesa da reforma das instituiçóes sociais, uma vez que estas estariam atuando em função dos critérios da razão moderna, em detrimento de aspectos subjetivos que deveriam ser incorporados.

Segundo esse pensador, encontra-se, no contexto da pós-modernidade, a presença de uma razáo sensível "[...] capaz de elaborar sobre os dados da sensibilidade intuitiva” (MAFFESOLI, 1994, p. 22), que se contraporia à "razão contábil" - característica da modernidade - e que pressuporia a ligaçáo entre a razão e o sentido, resgatando um valor que havia sido considerado ultrapassado no contexto da razão moderna. Essa perspectiva de razão traria o resgate do cotidiano, que no contexto da modernidade havia sido relegado e que se constitui, segundo ele, num dos elementos mais importantes da vida em sociedade. Esse resgate permite transpor o caráter fechado do pensamento político e econômico que não permitia ver outros aspectos que não os macros. Com a valorização do cotidiano, haveria a recuperaçáo dos valores sociais, e, portanto, o princípio do indivíduo presente na modernidade seria substituído pelo princípio das relaçóes e pela importância do afeto e da emoção.

Em se tratando de racionalidade é preciso que recuperemos mesmo que rapidamente, essa categoria a partir do pensamento de Max Weber (1991), pois tal é sua preocupação com a racionalidade característica do desenvolvimento do capitalismo e da economia, que não podemos falar dessa categoria sem nos 
referirmos à sua obra, até mesmo pela atualidade e permanente retomada de suas considerações.

$\mathrm{Na}$ obra Economia e Sociedade: fundamentos da sociologia compreensiva, que traz os principais conceitos de sua análise do capitalismo moderno, Weber (1991) considera a existência de dois tipos de racionalidade que orientam a ação humana em direção aos fins/objetivos visados: racionalidade formal e racionalidade material. $\mathrm{O}$ autor assim conceitua:

Chamamos racionalidade formal de uma gestáo econômica o grau de cálculo tecnicamente possível e que ela realmente aplica. Ao contrário, chamamos racionalidade material o grau em que o abastecimento de bens de determinados grupos de pessoas (como quer que se definam), mediante uma açáo social economicamente orientada, ocorra conforme determinados postulados valorativos (qualquer que seja a sua natureza) que constituem o ponto de referência pelo qual este abastecimento é, foi ou poderia ser julgado. Esses postulados têm significados extremamente variados. (WEBER, 1991, p. 52, grifo nosso).

A racionalidade formal ${ }^{1}$ por seu caráter previsível, técnico e calculável teria em vista o alcance de uma adequada ou de uma eficiente relação entre meios e fins, que implicaria em preocupaçáo com o dispêndio de recursos utilizados para a obtenção de um determinado fim. Logo, essa seria a racionalidade que orienta a gestão econômica.

Segundo Bellamy (1994), em sua análise do capitalismo moderno, Max Weber teria se preocupado com uma determinada exacerbação do processo de racionalidade formal e da burocratização, na medida em que esse processo ameaçava os ideais liberais no que se refere, principalmente, à liberdade individual e à disputa característica da economia de mercado. Este mesmo autor chama a atenção para o fato de que tais críticas estariam ligadas à preferência weberiana pelo capitalismo em detrimento do socialismo.

Pelas leituras realizadas, entendemos que Weber de fato levanta críticas às técnicas racionais do tipo formal, mas, ao mesmo tempo, num aparente paradoxo atribui ao desenvolvimento da racionalidade o alto nível de produtividade do capitalismo moderno e reconhece que, em tal estágio de 
desenvolvimento e industrialização, a economia não poderia ser orientada de outra forma. A racionalidade formal seria, portanto, na perspectiva weberiana, indispensável ao desenvolvimento do capitalismo.

Entendemos ainda que, a partir desse reconhecimento, Weber (1991) constata que a racionalidade formal estaria na direção prática dos fins econômicos, mas viria acompanhada da racionalidade material ${ }^{2}$, ou melhor, estaria orientando a ação humana tecnicamente, tendo em vista que os valores subjetivos, paixóes e sentimentos que poderiam, em contraponto à perspectiva da racionalidade formal, ser chamados de "irracionais", não desviassem o curso da ação:

Uma gestáo econômica é formalmente "racional" na medida em que a "previdência", essencial em toda economia racional, pode exprimir-se e de fato se exprime em consideraçôes de caráter numérico e calculável.

O conceito de racionalidade material, ao contrário, é inteiramente vago. Seus diversos significados só têm uma coisa em comum: que a consideração não se satisfaz com o fato puramente formal e (relativamente) inequívoco de que se calcula de maneira racional, com vista a um fim, e com os meios tecnicamente mais adequados possíveis, senão que estabelece exigências éticas, políticas, utilitaristas, hedonistas, estamentais, igualitárias ou outras quaisquer, e as toma como padrão dos resultados da gestão econômica - por mais racional, isto é, de caráter calculável, que esta seja do ponto de vista formal - procedendo assim de modo racional, referente a valores com racionalidade material referente a fins. Destes possíveis padrôes valorativos racionais nesse sentido, há em princípio um número ilimitado [...]. (WEBER, 1991, p. 37).

Decorre dessa perspectiva de controle da racionalidade formal sobre a material, e da eficiência das técnicas racionais no desenvolvimento da industrialização e da economia, que a ciência teria um papel preponderante orientando a açáo humana para o alcance racional de seus fins, apesar dos desvios da "irracionalidade humana":

Para a consideração científica que se ocupa com a construção de tipos, todas as conexóes de sentido irracionais do comportamento afetivamente condicionadas e 
que influem sobre a ação são investigadas e expostas, de maneira mais clara, como "desvios" de um curso construído dessa ação, no qual ela é orientada de maneira puramente racional pelo seu fim. $\mathrm{Na}$ explicação de um "pânico financeiro", por exemplo, é conveniente averiguar primeiro como se teria processado a ação sem influências de afetos irracionais, para registrar depois aqueles componentes irracionais como "perturbaçóes". Do mesmo modo, quando se trata de uma ação política ou militar, é conveniente verificar primeiro como se teria desenrolado a açáo caso se tivesse conhecimento de todas as circunstâncias e de todas as intençôes dos protagonistas e a escolha dos meios ocorresse de maneira estritamente racional orientada pelo fim, conforme a experiência que consideramos válida. Somente esse procedimento possibilitará a imputaçáo causal dos desvios às irracionalidades que os condicionam. Em virtude de sua compreensibilidade e de sua inequivocabilidade - ligada à racionalidade -, a construção de uma ação orientada pelo fim de maneira estritamente racional serve, nesses casos, à Sociologia como tipo ("tipo ideal"). Permite compreender a açáo real, influenciada por irracionalidades de toda espécie (afetos, erros), como "desvio" do desenrolar a ser esperado no caso de um comportamento puramente racional. (WEBER, 1991, p. 5).

O que podemos afirmar, então, é que, embora trate da racionalidade formal e da racionalidade material, há na análise weberiana da economia, ou em seu entendimento acerca da obtenção dos fins econômicos, uma preocupaçáo pretensamente maior com a valorização da racionalidade formal e da preocupação com a utilizaçáo da racionalidade material, que sendo "irracional" poderia "desviar" o curso da ação.

Em uma outra direção, ao empreender a crítica desse quadro de valorização de uma "razão contábil" e instrumental, que regula as instituições e a vida social a partir dos aspectos quantitativo e econômico, Maffesoli (1994) sugere a necessidade de reforma das instituiçóes sociais que estariam vivendo um momento de crise justificado pela crise do indivíduo da modernidade. Há, segundo sua perspectiva, a necessidade de reforma das instituiçóes sociais, porque estas estariam ainda organizadas com base nos valores da modernidade 
resistindo aos novos valores emergentes. Dentre esses valores, estariam os relativos ao indivíduo e aos pequenos grupos que esquecidos pela modernidade e resgatados pela condição pós-moderna, requerem uma nova concepção de racionalidade e novas formas de organização das instituiçôes que permitam a superação da ênfase no aspecto político, assim como a emergência do estético, que compreenderia "[...] o sensível, a comunicação, a emoção coletiva" (MAFFESOLI, 1994, p. 22).

$\mathrm{Ou}$ seja, se retomarmos a proposta de racionalidade inscrita na Modernidade, entendida a partir de Max Weber (1991), parece-nos cabível afirmar que haveria, na lógica pós-moderna, o entendimento da exacerbação da racionalidade formal - que Maffesoli (1994) chamaria de racionalidade contábil - na medida em que prioriza o calculável, o mensurável e o presumível em detrimento da racionalidade material. Aquela que Maffesoli (1994) chama de razão sensível deveria, assim, ser resgatada na organizaçấo das instituiçóes sociais e na forma de produção de conhecimentos.

Nesse sentido, é possível entender que, sob a perspectiva da pósmodernidade, as instituiçóes sociais estariam passando por uma crise de eficiência porque teriam se mostrado ineficientes os pressupostos técnicos que orientaram as relaçóes sociais, com base na chamada "razão contábil", conforme Maffesoli (1994), ou na racionalidade formal, segundo Weber (1991).

$\mathrm{Na}$ análise de Harvey (2000), podemos considerar que as mudanças nas instituiçôes sociais são requeridas no contexto da condição pós-moderna, em razão da valorização do local, do diferente e do heterogêneo, que exigiria a adaptaçáo do social e do individual às novas características que estariam sendo assumidas pelo capital. Nessa direção, a partir da perspectiva posta pelo autor, podemos dizer que o contexto neoliberal, sustentado pela condiçấo metodológica, teórica e política posta pela ideologia da pós-modernidade, exige a reforma das instituiçóes sociais, que não podem continuar sendo organizadas a partir dos princípios da modernidade fordista. Os sujeitos envolvidos com essas instituições estariam voltados para a valorização de seus aspectos subjetivos, para a "razão sensível" de Maffesoli (1994) ou a racionalidade material de Weber (1991), inaugurando uma nova relação com o espaço e o tempo, presentes no que Harvey (2000, p. 140) chama de acumulação flexível caracterizada por "[...] um confronto direto com a rigidez do fordismo".

Considerando, portanto, que uma dada transposição do taylorismo/ fordismo vem sendo empreendida a partir da introdução de novas formas de 
organização e de novas tecnologias no âmbito da produção, é possível dizer que a pós-modernidade e a acumulação flexível, que surge em meio às suas proposições, impóem um modo pós-moderno de pensar, sentir, agir e, desse modo, organizar/planejar, que tem em vista, dentre outros fatores, superar a rigidez que estaria presente na modernidade fordista e acelerar o tempo de giro da produção e do consumo.

É possível entender, desse modo, a acumulação flexível como resposta a uma crise do capital, e que tem em vista, dentre outros fatores, a necessidade de controle da interação entre trabalho vivo e trabalho morto, da qual não pode prescindir a racionalidade do modo capitalista de produção. Ou seja, a acumulação flexível visa, do ponto de vista do trabalho, a intensificação da extração de mais-valia; daí as proposições de mudanças no processo de trabalho, confirmando a sua importância vital para a reprodução/manutenção permanente do capitalismo.

Cabe considerar, então, a articulação do processo de mudanças na gestáo e no controle do trabalho, com um modelo político e econômico que se constitui a partir da década de 1970, sustentado pela perspectiva teórico-metodológica da pós-modernidade. Nesse sentido, a acumulação flexível integra a perspectiva ideológica pós-moderna e sua função de reprodução/manutenção do capital.

É possível afirmar que, embora tal como a condição pós-moderna, o modelo de acumulação flexível contraponha-se ao taylorismo/fordismo, reduzindo-o a uma metanarrativa, já que teria em vista a definição/adoção de uma única "maneira certa" de realizar o trabalho, o "novo" modelo que se pretende consolidar se constitui como uma metanarrativa, uma vez que a "flexibilidade" inserida nesse "novo" só teria em vista o alcance de uma verdade: adequar os índices de produtividade para atender a necessidade do capital. Desse modo, ideologicamente, num aparente paradoxo, teria em vista os mesmos fins da racionalidade fordista que critica.

Partindo da noção de que a acumulação flexível pressupõe - e até acirra a prescrição de tarefas, como ocorria no taylorismo/fordismo - é possível entender porque há alguns espaços para a "participação" do operariado:

A inovação requer, para o seu próprio aprimoramento, a participação, o interesse e o envolvimento dos trabalhadores e se ela pressupóe flexibilidade é preciso preparar todos para reagir às mudanças de demanda do 
mercado, dos produtos e dos processos.

O trabalhador necessita ser flexível, ou seja, saber lidar com uma variedade de funçóes, saber integrarse a diferentes formas de agregação e mobilização de trabalhos. (MACHADO, 1994, p. 181).

Ou seja, o controle dos trabalhadores pelo capital pede novos parâmetros, que muitas vezes aparecem mais sutis, já que, entre outras coisas, haveria uma relativa diminuição da parcelarização do trabalho e da presença do supervisor direto, presentes no taylorismo/fordismo, que incentiva a introdução de técnicas e de dinâmicas que possibilitariam a incorporação de novos valores, ligados a subjetividade, a emoção e ao sentimento; uma "nova racionalidade". É preciso entender, portanto, que são criados novos mecanismos de controle, muitos deles envolvendo uma determinada concepção de trabalho em grupo e de interferência nas áreas de planejamento a fim de regulamentar e, desse modo, controlar a participação. Essa lógica de gestão, de controle do trabalho e de racionalidade, que constituem a noção de acumulação flexível inerente aos pressupostos da condição pós-moderna, acompanha a necessidade da efemeridade, da volatilidade, da valorização da diferença, do planejamento a curto prazo e da descartabilidade no âmbito do consumo.

Se pretendemos entender a noção de racionalidade presente na reforma da Educação Básica, e de suas implicações para a gestão escolar, é indispensável que consideremos essas noçóes e essas transformações, e que ensaiemos algumas conclusóes acerca dessa "nova racionalidade" produzida e difundida no contexto da Pós-modernidade.

\section{As implicações da lógica pós-moderna para a gestão escolar: considerações sobre descentralização, participação e autonomia}

Ao tratarmos das políticas de gestão escolar observamos que, a pretexto de que o modelo e a organização burocrática sob a qual vinha sendo orientada a organização da escola, na direção dos princípios da racionalidade formal, seria responsável pela falta de qualidade da educação, são produzidos os discursos de ineficiência da escola e apresentadas proposições de inovação via a incorporação dos pressupostos de uma racionalidade mais sensível. Essa é a mesma perspectiva que embasa as estratégias de consolidação da atual configuração do modo 
capitalista de produção, contemplando a necessidade de controle do trabalho e da vida dos trabalhadores.

A reforma da gestão escolar pautada em critérios de eficiência e qualidade é assim sugerida e enfatizada pela alegação de que são problemas técnicos ou fatores internos que impedem o desenvolvimento eficaz dos sistemas e unidades escolares, pelo argumento de que a reforma da educaçáo básica não obteria êxito se não houvessem mecanismos eficientes de gerenciamento das ações implementadas e dos resultados obtidos.

No Brasil, percebe-se que, em meio a uma série de reformas propostas envolvendo dentre outros aspectos formação de professores, gestão escolar, avaliação e currículo, tendo em vista a qualidade da educação básica em atendimento ao compromisso firmado na Conferência Mundial de Educação para Todos, realizada em Jontiem em 1990, a gestão escolar recebe um enfoque particular levando em conta a necessidade da contribuição da educação para uma determinada perspectiva de desenvolvimento econômico e social. É possível identificar a partir da análise de documentos que se referem a Reforma da Educação Básica implementada nesta década, a sua sintonia com o processo de reconfiguração do modo capitalista de produção, que, amparado na ideologia da globalização e da pós-modernidade, define um novo padrão de Estado e de políticas sociais, sustentados pelos princípios do neoliberalismo e seu discurso de "ineficiência" do Estado e das instituiçóes a ele relacionadas, dentre elas, a escola.

De acordo com Krawczyk e Vieira (2010, p. 12):

A reforma educacional no Brasil iniciou-se na segunda metade da década de 1990 com o intuito de consolidar uma nova forma de gestão da educaçáo e da escola e, ao mesmo tempo, reverter o exíguo atendimento do ensino fundamental e médio bem como os altos índices de fracasso e evasão escolar.

Esse modelo de gestão, que teria em vista implantar a eficiência mercadológica acompanhada por uma "nova racionalidade", estaria pautado nos mecanismos de descentralizaçáo, autonomia e avaliação de resultados que trariam em seu bojo a preocupação com a qualidade e a equidade, sem esquecer a racionalização e a produtividade, ou seja, a eficiência. 
É possível verificar que atrás dessa alegação de ineficiência encontra-se a defesa da administração pública gerencial presente no Plano Diretor para a Reforma do Estado Brasileiro (BRASIL, 1995), contrapondo-se à administração burocrática que vinha orientando a administração pública e estaria pautada na rigidez de procedimentos e no excesso de normas e regulamentos, concentrando e centralizando funçôes no aparelho do Estado.

Sob a nova configuração da racionalidade, a pós-moderna, a administração pública gerencial seria o modelo adequado ao processo de democratização desencadeado pelos movimentos de oposição ao autoritarismo, repressão e centralização que imperavam no contexto da ditadura militar ${ }^{3}$. Materializar-seia nas políticas implementadas pelo neoliberalismo através dos mecanismos de descentralização, autonomia e controle de resultados, objetivando a eficiência mercadológica não apenas no que diz respeito aos aspectos técnicos que orientam a qualidade e a produtividade, mas também no que diz respeito às orientaçóes políticas e ideológicas que constituem o mercado.

Através da preocupação com os instrumentos de avaliação que substituiria o controle direto dos processo, baseado na supervisão nos moldes tayloristas, por estratégias que permitem aferir e comparar os resultados, estariam cobrando as responsabilidades dos envolvidos com as unidades escolares, sejam eles gestores, professores, funcionários, pais, alunos ou comunidade, em relação à qualidade e eficiência da educação.

É preciso destacar, contudo, que embora se critique o caráter punitivo desses mecanismos de avaliaçáo, valorizando a "flexibilizaçáo" do controle, o que concretamente se tem é a sua intensificação, o que significa, por sua vez, a intensificação do criticado postulado taylorista que recomenda a definiçâo da única maneira certa de realizar uma tarefa. Nessa direção, valoriza-se, premiamse "maneiras" diferentes, mas perseguem aquelas necessárias à eficiência do ponto de vista mercadológico; portanto, aquelas necessárias para a implementação da racionalidade enquanto adequação de meios e fins, que tem em vista a produçáo de resultados ótimos.

Para pontuar a questão da eficiência mercadológica, via a implementação dos mecanismos de descentralizaçáo, autonomia e avaliação, e, desse modo, da "nova racionalidade", parecem relevantes as reflexóes de Casassus (2002) a propósito das mudanças que estariam sendo processadas no quadro da gestáo educacional, particularmente no texto "Problemas de La Gestión Educativa en América Latina: La tensión entre los paradigmas de tipo A y el tipo B”. 
O autor, atribuindo à gestão educacional um caráter pragmático e político, discorre sobre as mudanças que se estabelecem ao longo do tempo no campo da gestão da educação articulada ao quadro da administração geral. Casassus (2002) entende que esse movimento é assinalado nas obras de Weber, Taylor, Fayol, Elton Mayo, Parsons, Bertalanfly, o que acaba, inclusive, refletindo na própria substituição do termo administraçáo por gestáo. Para ele os diferentes modelos que penetraram o movimento da gestáo da educaçáo, produzindo a passagem de uma perspectiva rígida, determinada e estável, a partir de uma ótica normativa, a perspectivas cada vez mais flexíveis e indeterminadas, que exigem processos constantes de ajuste, pautam-se em duas diferentes visões dos contextos em que se inserem as organizações. Essas visōes são por ele denominadas como tipos A e B.

Cada um desses tipos caracterizaria uma maneira de representar o mundo, o que parece compatível com a distinçâo comumente estabelecida entre os contextos da modernidade e pós-modernidade. Segundo Casassus (2002, p. 284), a cada representação corresponderia um modelo de gestáo:

[...] La visión paradigmática de tipo A representa un universo estable: en él, los supuestos acerca del ser humano son de tipo trivial y los referidos al contexto, son invariantes. En esta representación, el cambio es cumulativo en torno a ciertos objetivos preestablecidos. Estos supuestos requieren de un cierto tipo de teoría y de práctica gestionaría caracterizada por una perspectiva de tipo técnico-racionalista-linear.

La visión paradigmática de tipo B es la representación de un universo inestable; en el, los supuestos acerca del ser humano son de tipo no trivial y los referidos al contexto son fluidos, complejos e cambiantes. En la representación de tipo B, el cambio es turbulento y cualitativo. Estos supuestos requieren de otro tipo de teoría y de práctica gestionaría. Requieren de una práctica que se sitúe en una perspectiva que incorpore la diversidad y que se sitúe en un plano emotivo-no linear-holístico.

Assim como requerem modelos de gestão diferentes, esses tipos também requerem destrezas diferentes. Ao tipo B, por seu caráter indeterminado, incerto, flexível e imprevisível, são requeridas capacidades de autoconhecimento, análise, autoavaliação, comunicação, adaptação e criatividade. 
Apesar de afirmar que o modelo de gestão e de capacidades inspiradas no modelo B combina mais com a sociedade globalizada em que estamos inseridos, o autor afirma que a gestão dos sistemas educativos nos anos 1990, incluindo as políticas de descentralização, tem se centrado em uma gestão vinculada ao tipo $\mathrm{A}$, e que esse é um fato surpreendente, pois se há um setor social que necessite pautar-se no fator humano, que tem prioridade no modelo $\mathrm{B}$, é o setor educativo.

O que explica esse aparente paradoxo na análise de Casassus (2002)? Ao que parece as suas análises poderiam ser situadas entre aquelas que intentam estabelecer críticas sem, contudo, questionar a lógica central que produz as questôes e situações criticadas. Ou seja, a partir de uma perspectiva liberal, $\mathrm{o}$ autor reconhece o avanço das políticas estabelecidas no final do século XX em direçáo a outra gestáo educacional. Porém, numa perspectiva de avaliaçáo ideológica, considera que não estão sendo eficientes e que é preciso uma revisão dessas políticas para que possam se libertar da mera autorregulaçáo técnica, da linearidade dos processos e da racionalidade na concepção da conduta humana, características do que classifica como tipo A. Deveriam voltar-se para o desempenho das premissas do tipo B, o qual, por sua vez, constitui a visáo que corresponderia a uma perspectiva de democratização das organizaçóes e de valorização de seu caráter instável e dinâmico.

Casassus (2002) está sugerindo que, no contexto de implementação das políticas de gestão da educação, há uma tensão entre o que chama de tipo A e tipo $\mathrm{B}$, ou entre a racionalidade formal/contábil e a racionalidade material/ sensível, posicionando-se, sim, mas sem descartar, como aliás o fazem os documentos e a maioria dos autores que sustentam as reformas, as premissas do tipo A em defesa do tipo B. Esse tipo de apreensão contribui ideologicamente para a reprodução do capital, em sua necessidade de estabelecer aspectos/ variantes supostamente responsáveis pela não efetivação dos valores liberais e democráticos ou de desenvolvimento pleno das potencialidades do homem, favorecendo a permanente canalizaçáo de esforços em torno da educaçáo ou de outras variantes eventualmente eleitas.

\section{Considerações finais}

Poderíamos concluir, portanto, a partir dessas consideraçôes, que essa tensão entre diferentes noções de racionalidade, raramente explicitadas ou 


$$
\text { cas de gestão escolar }
$$

mesmo percebidas, é de base ideológica visando e resultando na responsabilização de determinados aspectos/fatores/estratégias/variantes pela "irracionalidade" do capital em seu processo sócio-metabólico de reprodução (MÉSZÁROS, 2002). Assim como é ideológica também a substituição do termo administração que teria, segundo essa lógica, um caráter normativo e adequado a um contexto estável e determinado, pelo termo gestáo $0^{4}$, próprio de um contexto flexível, indeterminado e que favoreceria a subjetividade 5 .

Para implementar a pretendida Reforma da Educação seria necessário, segundo a lógica orientadora oficial, rever a perspectiva de organizaçáo burocrática e ineficiente sob a qual a escola vem sendo administrada e implementar em seu lugar uma concepção de gestão mais flexível, "sensível" e capaz de tornar a escola um espaço que eduque para a cidadania e para a convivência em uma "sociedade mais justa e igualitária", marcada pela existência do diferente.

O que explica a preocupação com a eficiência mercadológica e a introdução de mecanismos que tenham em vista atingir essa eficiência e, portanto, a incorporação dos pressupostos de flexibilização das formas de gestão e controle do trabalho, assim como da preocupaçáo com o controle de qualidade do produto características da acumulação flexível, é a necessidade posta pelo modo capitalista de produção de preservar a interação entre as diferentes organizaçôes sociais, a fim de que se reproduza uma dada lógica de comportamento e de disciplina.

O que se pode observar é que, no contexto de uma "nova racionalidade", valoriza-se a qualidade do produto oferecido e confere-se um dado poder de decisão aos envolvidos no espaço direto e imediato da produção, tendo em vista a otimização de recursos, sustentada na noção de "parceria" na implementação de objetivos estabelecidos em "coautoria" e a consequente "corresponsabilidade" pelos resultados.

Essas concepções sustentam-se na ideia de que não são os recursos financeiros que melhoram a qualidade da educação, mas o elemento humano. É essa ideia que justifica, então, o investimento na figura do diretor, objetivando o desenvolvimento de habilidades gerenciais.

Para compreender a "nova racionalidade" proposta para a organização dos sistemas e unidades educacionais devemos tomar o conjunto de reformas implementadas na década de 1990, a partir da perspectiva sistêmica proposta 
para superar os limites do padrão de racionalidade fordista, e a partir da conjugação de esforços que, girando em torno do elemento humano, poderiam contribuir para o processo mais amplo de ajustes requeridos por uma sociedade flexível.

A "novidade" desse padrão de racionalidade residiria na permanente necessidade técnica e ideológica de engendrar sistêmica e sinergicamente novas configuraçóes para que as diferentes organizaçóes e instituiçóes constituam e materializem uma dada concepção de eficiência e produtividade.

Logo, é possível concluir que a racionalidade pós-moderna no campo da gestão dos sistemas educacionais e das unidades escolares se manifesta, como no movimento histórico produzido em torno da administração, a partir da valorização de elementos subjetivos que possibilitariam a negação do estático, do meramente estabelecido, calculável e presumível, em direção ao flexível, ao imprevisível, ao incerto, ao global, tendo em vista assegurar todos os espaços/ oportunidades de efetivaçáo dos interesses hegemônicos do capital.

A distinção entre essas "racionalidades" e mesmo a aparente preocupação weberiana com a exacerbaçáo da burocracia e da racionalidade formal são ideológicas e propostas com o fim de prescrever a importância da técnica para a orientação da ação humana em seus fins econômicos. A preocupação de Maffesoli (1994) com a exacerbação da racionalidade contábil e da necessidade de a ela se sobrepor uma razão sensível é um artifício ideológico para desviar o foco de análise da racionalidade enquanto intrínseca ao capitalismo e colocá-lo como um erro de estratégia que precisa ser corrigido para que se possa retomar o desenvolvimento.

É preciso, no entanto, no caso da análise de Weber (1991), chamar a atençáo para o fato de que Maffesoli (1994) não desconsiderou uma possível interpretaçáo crítica de sua compreensão de racionalidade e sua relação com os valores "irracionais", enquanto desvios da ação humana em direção aos fins visados. Ao tratar da relação entre a racionalidade formal e a racionalidade material, e do predomínio da primeira na gestão econômica, preocupou-se em justificar que:

Nessa medida, e somente por esse motivo de conveniência metodológica, o método da "Sociologia compreensiva" é "racionalista". No entanto, é claro que esse procedimento náo deve ser interpretado como 
preconceito racionalista da Sociologia, mas apenas como recurso metodológico. Náo se pode, portanto, imputarlhe a crença em uma predominância efetiva do racional sobre a vida. Pois nada pretende dizer sobre a medida em que na realidade ponderaçôes racionais da relação entre meios e fins determinam ou não as açóes afetivas. (WEBER, 1991, p. 5).

Mészáros (2004, p. 4), chamando a atenção para o caráter ideológico dessas proposiçóes que teriam sido elaboradas visando ao socialismo como principal adversário, afirma a respeito da citaçáo acima apontada:

De fato, é mais conveniente ver um pânico na bolsa de valores como causado pela "irracionalidade", tendo ao fundo o pressuposto weberiano do capitalismo como um cálculo racional. Entretanto, como podemos mais uma vez observar, esta conveniência é puramente ideológica. Weber trata todos os sintomas de crise da ordem sócio-econômica capitalista eternizada como meros desvios em relaçáo a sua racionalidade intrínseca enquanto sistema total.

Ou seja, tanto Max Weber (1991), ao enfatizar a racionalidade da ação humana, quanto Maffesoli (1994), ao propor um novo foco para a racionalidade, sustentam ideologicamente a necessidade da permanente reprodução do modo capitalista de produção, o qual sobrevive, entre outras condições, a partir da produção de uma ideologia que o sustente e que seja capaz de, nos momentos de crise, engendrar discussōes que, embora muitas vezes tratem de aspectos pertinentes ao capital, não questionem a sua existência e, inclusive, reforcemna. É o que faz, por exemplo, Weber (1991) ao tratar da racionalidade e de seus "desvios"; transfere a responsabilidade por "resultados" inadequados para uma dada ineficiência da ação humana, que estaria se deixando levar pelos seus interesses subjetivos e por sua incapacidade no trato com a técnica racional. Logo, é possível dizer que, sob as duas perspectivas apontadas, a crise do capital é determinada por um "erro" de racionalidade.

Assim, a preocupação de Maffesoli (1994) com a exacerbação da racionalidade contábil e da necessidade de a ela se sobrepor uma razão sensível capaz de valorizar a iniciativa e a criatividade do elemento humano é um artifício 
ideológico lançado mão para desviar o foco de análise da racionalidade enquanto intrínseca ao capitalismo e colocá-lo como se fosse um erro de estratégia que precisa ser corrigido para que se possa retomar o desenvolvimento. E é tambem um mecanismo que, em última instância, atribui ao elemento humano a responsabilidade pelos resultados e, logo, pela mudança ou permanência da falta de qualidade e eficiência.

Assim, podemos afirmar que a análise dos documentos elaborados no contexto da década de 1990 leva a constatação de que as categorias descentralização, participação e autonomia e as chamadas instituições auxiliares da escola nas políticas de gestão escolar são enfatizadas como soluções para uma suposta ineficiência da escola, e na medida em que são implementadas assum os valores da diversidade, tolerância, criatividade, flexibilidade e inovação que caracterizam a lógica racional pós-moderna.

\section{Notas}

${ }^{1}$ Pelo que pudemos concluir seria aquela que Maffesoli (1994) trata como razão contábil.

${ }^{2}$ Esta seria na proposição de Maffesoli (1994) a razão sensível.

${ }^{3}$ Oliveira (2002, p. 136) chama atenção para a gestão democrática que emergiu nesse processo de democratização da sociedade brasileira, ao afirmar que: "[...] o termo gestáo democrática da educaçáo emerge significando a defesa de mecanismos mais coletivos e participativos de planejamento e administração escolar. A gestão democrática da educaçẫo passa a representar a luta pelo reconhecimento da escola como espaço de política e trabalho, onde diferentes interesses podem se confrontar, e ao mesmo tempo, dialogar em busca de conquistas maiores. A defesa da autonomia, entendida como o espaço de explicitaçáo da política, da possibilidade da própria escola refletir sobre si mesma e adequar-se à realidade local, com exercício de autodeterminação, vai resultar na busca de novas formas de gestão escolar".

${ }^{4}$ A esse respeito cabe considerar o que diz Oliveira (2002, p. 136-137): “[...] Nos últimos quinze anos, vimos pouco a pouco a Administração Escolar ir arrefecendo-se ante a emergência da gestão educacional. Embora haja pouca pesquisa especificamente sobre o assunto, o que se percebe é 
um entendimento quase tácito entre os pesquisadores da área de que o termo 'gestão' é mais amplo e aberto que 'administração', sendo ainda o segundo carregado de conotação técnica, o que predominou nas décadas anteriores como orientaçáo para as escolas. Nesse sentido, a gestáo implicaria participação, e, portanto, a presença da política na escola. Já o termo 'escolar' vai sendo substituído pelo 'educacional', justamente pela compreensão de que a educação não se realiza só na escola e que, por isso, os sistemas não são escolares, mas educacionais".

${ }^{5}$ A identificação desse caráter ideológico, necessário ao capital, particularmente no que se refere à educação, não é novidade. Rosar (2002), por exemplo, questiona a existência de novos paradigmas na política e na administração da educação e em que trata das políticas de reforma da educação que supostamente fariam emergir uma dada democratização da escola pública e a expansão de um determinado modelo de gerenciamento.

\section{REFERÊNCIAS}

BELLAMY, Richard B. Liberalismo e Sociedade Moderna. São Paulo: Editora da UNESP, 1994.

BRASIL. Ministério da Administração Federal e da Reforma do Estado. Plano Diretor da Reforma do Aparelho do Estado. Brasília, DF, nov. 1995.

CASASSUS, Juan. Problemas de la gestión educativa en América Latina: la tensión entre los paradigmas de tipo A y el tipo B. Em aberto, Brasília, DF, v. 19, n. 75, p. 49-69, jul. 2002.

FÉLIX, Maria de Fátima Costa. Administração escolar: um problema educativo ou empresarial? São Paulo: Cortez, 1986.

HARVEY, David. Condição pós-moderna. São Paulo: Loyola, 2000.

KRAWCZYK, Nora Rut; VIEIRA, Vera Lúcia. A reforma educacional na América Latina nos anos 90: uma perspectiva histórico-sociológica. Revista Latinoamericana de Educación Comparada, Buenos Aires, ano 1, n. 1, 2010. 
MACHADO, Lucília Regida de Souza. A educação e os desafios das novas tecnologias. In: FERRETI, Celso João et al. Novas tecnologias, trabalho e educaçâo: um debate multidisciplinar. Petrópolis, RJ: Vozes, 1994. p. 169188.

MAFFESOLI, Michel. Conferência: Estudo crítico das ciências, da formação e das condições do conhecimento científico. In: COLÓQUIO PANAMERICANO DE INVESTIGAÇÃO EM ENFERMAGEM, 6., 1994, Ribeirão Preto. Anais... Ribeirão Preto, SP: EERP, 1994.

MÉSZÁROS, István. Para além do capital: rumo a uma teoria da transição. Campinas, SP: Boitempo, 2002.

MÉSZÁROS, István. O poder da ideologia. São Paulo: Boitempo, 2004.

OLIVEIRA, Dalila Andrade. Mudanças na organização e na gestão do trabalho na escola. In: OLIVEIRA, Dalila Andrade; ROSAR, Maria de Fátima Félix (Org.). Política e gestão da educaçâo. Belo Horizonte : Autêntica, 2002. p. 125-143.

ROSAR, Maria de Fátima. Félix Existem novos paradigmas na política e na administração da educação? In: OLIVEIRA, Dalila Andrade; ROSAR, Maria de Fátima Félix (Org.). Política e gestão da educação. Belo Horizonte : Autêntica, 2002. p. 157-173.

TRAGTENBERG. Maurício. Relaçôes de poder na escola. In: OLIVEIRA, Dalila Andrade; ROSAR, Maria de Fátima Félix (Org.). Política e gestão da educaçâo. Belo Horizonte: Autêntica, 2002, p. 11-16.

WEBER, Max. Economia e sociedade: fundamentos da sociologia compreensiva. Tradução de Regis Barbosa e Karen Elsabe Barbosa. Brasília: Editora da UnB, 1991. 


\section{El giro para el siglo XXI y las explanaciones de las concepciones posmodernas en las políticas de gestión escolar}

\section{Resumen}

Este artículo reflexiona sobre la reforma de la gestión escolar de la década de 1990. Esta reforma se implanta bajo el argumento de que es necesario modernizar la perspectiva de la gestión de la escuela para que sea eficiente. Para desarrollar el análisis realizado a partir de la revisión de la literatura, el artículo analiza la sustitución del taylorismo/fordismo por el paradigma de la acumulación flexible, que tiene un "nuevo" modelo de gestión y control. Este modelo estaría pautado por la ideología de la posmodernidad. Para evidenciar esta conclusión se discute la lógica de gestión/control del trabajo guiado por la racionalidad postmoderna que acompaña a la recuperación de los ideales del liberalismo, tratando de mostrar las implicaciones que esta lógica produce en el ámbito de la gestión escolar. Se observa que la organización escolar incorpora este movimiento a través de la difusión de hábitos y actitudes y también de la adopción de los elementos utilizados por la gestión que desarrolla en un conjunto de organizaciones sociales. En este sentido, es tratada la apreciación del elemento humano, la implementación de mecanismos de evaluación, la descentralización
The turn of the $21^{\text {th }}$ century and the ramifications of postmodern conceptions of school management

\section{Abstract}

This paper presents reflections on the reform of school management from the 1990s This reform is implanted under the argument that it is necessary to modernize school management perspective to make it efficient. To develop the analysis performed from literature, the article revisits the replacement of Taylorism/Fordism by the paradigm of flexible accumulation that presents a "new" management and control model.This model would be guided by the ideology of postmodernity. To make this conclusion evident it is important to discuss the logical management/control of labor guided by the post-modern rationality which accompanies the recovery of the ideals of liberalism, trying to show the implications that this logic produces within the school management.It is observed that the school organization incorporates this movement through the diffusion of habits and attitudes and also from the adoption of the elements used by management that develops a set of social organizations.In this sense, some fundamental categories which are essential to the management reform are treated, for instance: the appreciation of the human element, the implementation of evaluation mechanisms, decentralization and 
y la autonomía, categorías estas, fundamentales para la reforma de la gestión en revisión. Como uno de los resultados evidenciados, se destaca que la tensión entre la "racionalidad" tratado por la posmodernidad es de base ideológica y su objetivo es responsabilizar a los individuos por los resultados alcanzados.

Palabras claves: Gestión escolar. Racionalidad. Posmodernidad.
autonomy.As one of the highlighted results, it is focused that the tension between the "rationality" treated by postmodernity has ideological basis and aims accountability of individuals for results.

Keywords: School management. Rationality. Postmodernity.

\section{Isaura Monica Souza Zanardini}

E-mail:monicazan@uol.com.br

\section{Maria Elizabete Sampaio Prado Xavier}

E-mail: betespxavier@hotmail.com

Enviado em: 1/4/2013

Aprovado em: 23/5/2014 